\title{
Guidelines for Industrial Symbiosis-a Systematic Approach for Content Definition and Practical Recommendations for Implementation
}

\author{
João Azevedo ${ }^{1}$ (D) $\cdot$ Juan Henriques ${ }^{1} \cdot$ Marco Estrela $^{2} \cdot$ Rui Dias $^{1} \cdot$ \\ Doroteya Vladimirova $^{3} \cdot$ Karen $_{\text {Miller }}{ }^{3} \cdot$ Muriel Iten $^{1}$
}

Received: 30 October 2020 / Accepted: 27 January 2021 / Published online: 15 February 2021

(C) The Author(s) 2021

\begin{abstract}
The increase of industrial symbiosis (IS) activities around the world has strongly contributed to promote awareness among companies on the benefits of this business model and, consequently, their interest to apply/incorporate dedicated IS actions in their activities. In most cases, companies assume self-learning and ongoing approaches for the adaption of synergies, ignoring some fundamental aspects as the full spectrum of considerations regarding these processes. Unexpected barriers frequently appear during the implementation process and become hardly overcome due to incomplete systematic approaches and the lack of information. In this context, it is important to promote effective and sequential guidance procedures regarding IS implementation processes to support companies in their transition to full IS processes implementation. This paper aims to advance the synergy implementation emerging process, through the identification, promotion, and definition of the core steps to be considered in an IS implementation process. This study is based on a comprehensive perspective for the definition of contents to be considered in a step-by-step guideline that includes the different theoretical, technical, and strategic approaches for large-scale IS promotion. The main outputs of this paper are a final set of independent and sequential information clusters, their associated contents identification process, and a comprehensive description of the systematic approach used to support companies in the implementation of their pre-identified stages. The guideline methodology proposed in this study is an important support tool for companies, practitioners, and agents intending to initiate IS synergies implementation and also a strong contribution to the development of complementary guidance activities regarding IS implementation process.
\end{abstract}

Keywords Industrial symbiosis · Guideline · Companies · Synergy implementation

João Azevedo

jdazevedo@isq.pt

Extended author information available on the last page of the article 


\section{Introduction}

Industrial symbiosis (IS) is a sub-field of industrial ecology (IE) that started to appear in the early 1970s [1]. In practical terms, this circular business model aims to redirect wastes and raw materials from a certain process to be used in another process [2]. These exchanges or synergies can occur in different perspectives, such as intra-company (within the same company $[3,4]$ ), inter-companies (among different companies) [4, 5], eco-industrial parks (industrial ecosystem) [5, 6], or urban IS $[5,7]$. The literature suggests that through the implementation of this business model, the companies are able to generate environmental, economic, and social benefits [8]. IS large-scale implementation has been emphasized in the last 10 years [9], especially in the European [10] and Asian continents [11], where it has had greater application. Despite the huge potential for the IS implementation, its effective application seems to be not fully exploited and companies are still facing problems/limitations in the emerging process [12]. Main barriers for effective synergies implementation have been evaluated in the context of different studies [12-15] where political, social, economic, and technological factors were found to be the most important clusters to consider. In order to overcome these barriers at their different levels, several studies have been giving particular attention to the characterization of the IS emerging process, with special focus on the understanding of the fundamental aspects, such as intervening factors $[12,16,17]$ (enablers, barriers, triggers, etc.), networks promotion $[18,19]$, and associated business models $[4,5,20]$. However, it is necessary to identify the actions required to overcome the different levels of barriers and promote IS practical implementation in a structured and simplified manner. For this reason, the scientific community has developed practical studies on the IS approaches validation [3, 11, 21], analysis and characterization of case studies [22-24], and promotion of facilitating frameworks at several levels $[9,25,26]$. This has allowed the consolidation of a robust base of recommendations for IS $[27,28]$ which have been mainly based on transversal aspects such as the perspective of technical implementation, policy promotion, and emerging process facilitation. Nevertheless, a fundamental issue emerged at this point: how to translate those recommendations into practical and ready-to-use documents. As an answer for this, the concept of guidelines appears, defined as the information that intends to advise people on how something should be done or what something should be [29] to support potential users in the understanding and application of actions at the different stages of an implementation process.

However, this matter has been approached by several studies that proposed guidance documents for IS, mainly focusing independently on the perspective of concept and best practices introduction, business development and facilitation, policy recommendations, and the operational aspects of IS. For instance, Johnsen et al. [30] identify a set of barriers for realizing IS exchanges and propose potential reference topics to be addressed in future guidelines regarding the definition and benefits of IS, the existence of local facilitating programs, and what to be aware of in case companies decide not to take advantage of them. From a business perspective, Fraccascia et al. [4] promoted a symbiotic business model guide directed for firms, recognizing several business models for both firms producing wastes and firms using wastes as inputs. Moodie et al. [31] have developed a policy brief based on three good practice examples of IS in the Baltic Sea Region and outlined practical guidelines for public authorities and organizations on how to develop and implement IS Ecosystems. In a different perspective, Holgado et al. [32] have presented a stepwise process focused on the identification and analysis of potential symbiotic solutions. The so-called Tools for IS (T4IS) [33] constitutes a self-guiding process for companies to engage in industrial symbiosis and develop symbiotic 
exchanges by the identification of potential alternative uses for unexploited wastes. Moreover, the Washington State Department of Commerce et al. [34] developed a guideline report which addressed the concept of industrial symbiosis, exploring implementation models and case studies in order to derive recommendations for policy frameworks and facilitation programs. Regarding R\&D projects, such as SHAREBOX [35] and FISSAC [36], several efforts have been made to extract core lessons from research and generate recommendations and explore the benefits of IS [27]. The SYMBI project has also produced a theoretical base for the IS implementation, developing benchmarking guidelines on ecosystems of byproduct and energy exchanges based on the lessons learned from various case studies and expert consultation [37].

The above-presented approximations regarding the guiding process for IS had contributed to a promotion, namely, on the definition of the concept of IS, identification of associated benefits and challenges, the perspective of business development, emerging process facilitation, and the support on the technical side of the synergies identification process. Nevertheless, none of them establish a clear vision of the different sequential intervention/guidance levels required to promote a full IS implementation. In this sense, no study that compiles and presents a practical systematic approach to support practitioners/companies in the process of achieving reliable and permanent synergies was identified. A gap in the development of dedicated practical IS guidelines for large-scale implementation has therefore been identified. Such multi-target guideline approach should be able to guide practitioners (enterprises, governments, and community of practice) through all stages of the implementation process in order to minimize/mitigate the potential risks associated [38] by covering the full set of key support aspects still in need. Some of those aspects have been already identified by the authors in some of their studies [39, 40], including the awareness on the benefits of IS potential/implementation at the company level, the identification of intervening factors and their facilitating strategies, the validation and a full assessment of synergy opportunities (technical, environmental and economic), and a clear set of recommendations for implementation at different management levels $[38,41]$. In fact, an extensive review of all European initiatives in the field of industrial symbiosis, developed in 2020 by the European Commission, points the need to fulfill this gap [27]. Thus, this paper reiterates the creation of IS implementation guidelines in order to drive the understanding and acceptance of IS in an accelerated means. It also considers that the promotion of guideline, eventually, could consolidate the first theoretical base to support the implementation in a handbook.

This paper aims to advance the synergy implementation process, through the identification of the core intervention areas/stages to be considered in a guideline for IS by promoting the principles that should guide the companies in all the stages of the IS emerging process, defining target scenarios of potential large-scale implementation and supporting them by the identification of a multilevel set of recommendations. The present study integrates some of the core findings of the multidisciplinary research analysis carried out in the context of the developments of the ongoing study [42].

The structure of this paper is as follows: the Introduction section is an introductory section explaining the scope of the study, its importance, and its technical objectives; the Systematic approach section describes the systematic approach that supports the study; the Results part definition section describes the results on main information clusters defined for IS guidelines promoted in this paper including a vision, ideal scenarios, and recommendations for largescale IS implementation; and the fourth and last section presents relevant conclusions and future recommendations. 


\section{Systematic Approach}

The systematic approach intends to overcome the need of establishing the different levels of intervention and guidance required in a full IS process implementation. To achieve the stated objective and solve the questions of how and why to define those levels, three main stages have been considered and integrated into a single systematic approach as shown in Fig. 1.

where

- Information sources and methods: refers to the identification of all information sources and contents available and produced in the scope of a study performed by the authors [42] including the information gathering instruments and methods used to support the research.

- Content definition: refers to the selection and compilation of the most relevant information contents previously identified and the definition of the associated technical objective that will guide the final clustering process definition.

- Practical output: refers to the final format and organizational presentation structure for the different contents previously idealized/identified.

A detailed description of each stage is presented in dedicated sections below.

\section{Information Sources and Methods}

The main objective of this stage is to consider and evaluate all of the study's outcomes in order to be integrated into the future guidelines as each one of them contributes to different stages of the IS process implementation. From a global perspective, the study outcomes can be categorized into three main groups as listed in Fig. 2.

Step I is composed of 3 groups as described below.

i) Theoretical approach on resources and synergies, including lessons learnt and best practices [39]; key technologies and intermediaries for IS ideation and implementation [43]; the prevention and mitigation of IS implementation risks [38]; and the pathways to increase industrial symbiosis implementation including tools and methods [44].

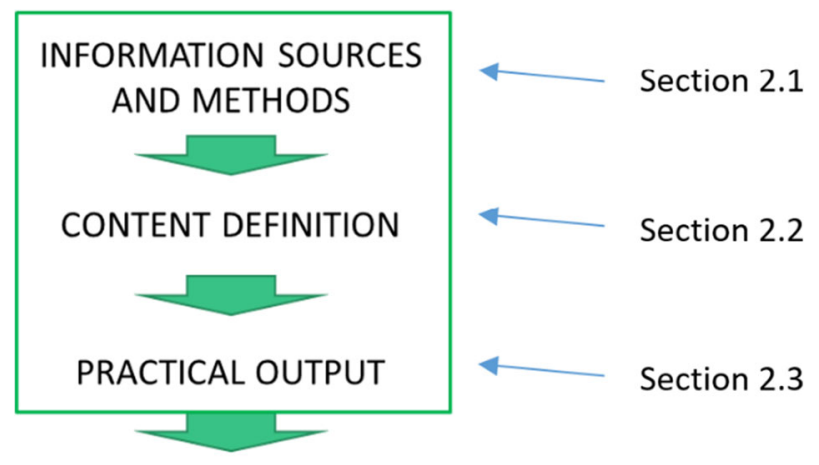

IS GUIDELINE STAGES DEFINITION

Fig. 1 Methodological framework for IS guideline stages definition 


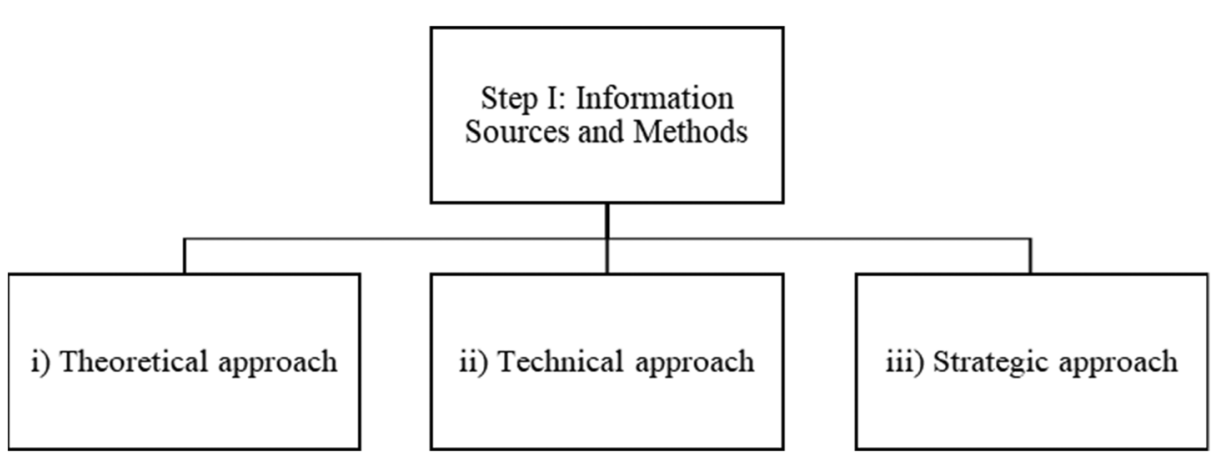

Fig. 2 Step I. Information sources and methods

ii) Technical approach and the practical assessment of the potential for industrial symbiosis, including the definition of the most promising synergies [45]; an associated technology database and guide for upgrading[46]; their environmental impact assessment [47]; their socioeconomic impact assessment [48]; and finally their quantified potential of Industrial Symbiosis in Europe [49] based on the integration of previous analysis.

iii) Strategic support approach to establish the action plan for industrial symbiosis in Europe, including the overall strategy and recommendations to foster a wide application of industrial symbiosis at local, regional, and European levels [50].

The main results obtained from previous outputs consider two main types of information: the one associated with technical knowledge/developments mostly associated with i to iii, and the ones associated with the so-called tacit knowledge built upon complementary studies interactions. Regarding the technical developments available on the above presented reports, they were gathered by the use of different acquisition methods:

Literature review in which a total of 210 references (peer-reviewed papers) were captured through the database of Science Direct, Scopus, and the internet search engine machine Web of Science, with the keyword "Industrial Symbiosis." After critical reading and content analysis, it was obtained a final sample of 85 references [39]. Others sources of information (non-scientific publication) like technical reports, EC reports, and European project deliverables were also considered; dedicated enquires in which expert consultation was performed through a dedicated inquiry directed to businesses and practitioners that are involved in various stages of IS implementation - from emergent to fully implemented - in all industrial sectors. This survey incorporated a total of 24 direct questions with multiple choice, regarding various topics such as IS a key factor, incentives, intermediaries, benefits, and difficulties for IS implementation [39]; triangulation methodology in which the results of the two previous steps where triangulated. This methodology allows to uncover the main findings by means of data crosschecking from the different sources considered.

The collaborative aspect of the study [42] allowed obtaining complementarily relevant nontechnical outcomes. Highly associated with tacit knowledge, the results were mainly obtained by the interaction with study partners, IS expert consultation, and advisory board recommendations. These results, mostly qualitative, are supported by a set of complementary recommendations and good practices, the practical approach of the technical developments, resulting in coherent end user-focused approximations. Table 1 presents a summary of the main information sources type and acquisition methods used during the study. 
Table 1 Resume of information sources and acquisition methods used in different study stages

\begin{tabular}{|c|c|c|c|c|}
\hline Stages & $\begin{array}{l}\text { Information } \\
\text { type }\end{array}$ & Information source & Acquisition method & Reference \\
\hline $\begin{array}{l}\text { i) Theoretical } \\
\text { approach }\end{array}$ & $\begin{array}{l}\text { Technical + } \\
\text { tacit }\end{array}$ & $\begin{array}{l}\text { Best practices for industrial symbiosis; } \\
\text { Key factors identification (Enablers, } \\
\text { barriers and triggers); } \\
\text { Industrial Symbiosis Incentives assessment }\end{array}$ & $\begin{array}{l}\text { Literature review } \\
\text { Dedicated enquires } \\
\text { Case study analysis }\end{array}$ & [39] \\
\hline $\begin{array}{l}\text { ii) Technical } \\
\text { approach }\end{array}$ & $\begin{array}{l}\text { Technical }+ \\
\text { tacit }\end{array}$ & $\begin{array}{l}\text { Technology database and guide for } \\
\text { upgrading; } \\
\text { Synergies environmental impact } \\
\text { assessment (life cycle assessment); } \\
\text { Synergies socio-economic impact assess- } \\
\text { ment (market value analysis) }\end{array}$ & $\begin{array}{l}\text { Synergy mapping } \\
\text { activities; } \\
\text { Synergies database } \\
\text { consultation; } \\
\text { Synergy validation } \\
\text { methods and tools }\end{array}$ & $\begin{array}{c}{[45,46,} \\
51]\end{array}$ \\
\hline $\begin{array}{l}\text { iii) Strategic } \\
\text { approach) }\end{array}$ & $\begin{array}{l}\text { Technical }+ \\
\text { tacit }\end{array}$ & $\begin{array}{l}\text { Overall strategy and recommendations for } \\
\text { IS }\end{array}$ & Expert consultation & [39] \\
\hline
\end{tabular}

\section{Content Definition}

Once all valuable information sources have been identified, it is necessary to define how to integrate them into a coherent and sequential structure. The main objective of this stage is to identify complementary contents available from different sources in structured and compact parts of information. Each one of the parts should provide a sequential logic on the provided contents and support practitioners in a specific stage of the IS implementation process avoiding duplicity or overlapping of contents during the process. The integrated sequence of parts, therefore, establishes the full guidelines for IS implementation. Figure 3 resumes the main steps used for content definition. A dedicated description is provided in the following section.

i) Technical objective: Considering the large amount of information generated during the study, the first step is to analyze all information sources available and compile the core output ideas and contents produced in a set of core output technical objectives that translate into a representative way the full process of IS implementation. This initial approach allowed to clearly define the initial guidance roadmap needs for IS process

Fig. 3 Content definition methodology scheme

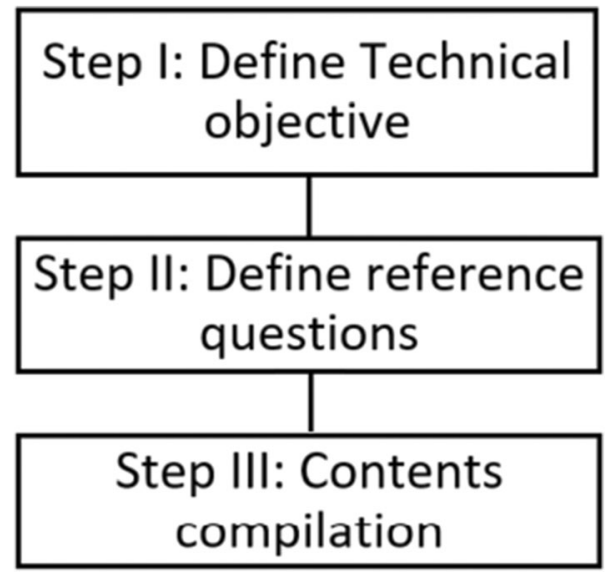


implementation, starting from the generic contextualization of industrial symbiosis, crossing through the most important factors and strategies to be considered, operational firmlevel implementation guidance, and a global vision on the EU potential and future scenarios for the full IS process Implementation. The final result of this stage is resumed in Table 2, by the generic technical objective identification. A more detailed description of each technical objective is presented in section 3 .

ii) Reference questions: Once the main technical objectives have been named and defined to be addressed in the future guideline parts, specific objectives were complementarily identified to support the specificities of contents definition of each one. A dedicated key reference question associated to each specific objective was so created to guide and simplify the content development process. Between two and three questions for each technical objective have been designed and validated with relevant stakeholders involved in the different stages of previous study activities (practitioners, advisory board, researchers and technicians). A dedicated check list template was created for the validation process by each stakeholder. It was sequentially organized according to each part, including the specific sets of input information sources, their proposed technical and specific objectives, and their associated reference questions. A final yes/no applicability criterion and a qualitative complementary recommendations section were used for final validation assessment.

iii) Based on the final questions to be addressed, the selection and compilation of the final output contents have to be included in each part. The general objective of this stage is to compile and crosscheck the main relevant information available and technically establish the final output contents by associating them with the information sources. This process is highly dependent on the information sources available, requiring dedicated approximations for each part target and several interactions with stakeholders. Alongside the definition of the contents, individual organizational information structures have been selected according to information volume, complexity, and expected visual impact of each part.

\section{Practical Output Format}

Once all parts were defined, characterized, and validated, the third stage is related to the definition of the final outputs presentation format. The final format selection has been done in order to present all contents in a very visual, compact, and appellative manner that could be easily accessed sequentially, or independently by any potential user/interested party without dismissing the project output format. In this sense, the selected contents were designed to be included in an interactive guideline document that compiles all results and procedures in a single guideline for IS Implementation document; provides a detailed characterization of each part including the methodological approach used and final output achieved; facilitates the access and further utilization of individual documents produced; and promotes and disseminate the study developments beyond classical reports format. The final practical output was therefore a fully interactive document designed to integrate external links for independent access to stand-alone output document formats that could be accessed individually by users including the systematic approach used. These standalone documents, developed to each preidentified part, were designed in a specific output format composed of generic and specific contents from short animation video to PDF documents. The final practical outputs selected are presented in section 3 . 


\section{Results Part Definition}

A total of five independent parts have been finally defined to be considered in the full guideline document for IS implementation. Each one of them corresponding to a specific stage of the IS process in a practical implementation perspective being organized sequentially to provide a clear step by step methodology approach for practitioners. Table 2 presents the final definition adopted for each part, summarizing their main technical objective as well as their specific objectives.

Part1 is defined as the "IS overview," it has been prioritized as the basis of any potential IS activity and pretends to introduce IS in an overall perspective, not only to raise awareness on the topic but also to establish a coherent and understandable starting point. Part 2, defines "intervening factors" intending to cover the full spectrum of variables that can positively and negatively affect the full implementation process. Part 3 defines the "overview of strategies for IS projects implementation" by compiling a comprehensive set of actions and strategies that have been identified during this study and recognized to be crucial at different companies and regional/national and European levels. Part 4, "synergy technical implementation," comprehends all issues associated with the technical standpoint of a synergy, since its identification to its implementation including relevant tools and practical considerations. Part 5, "future scenarios," defines the reference target scenarios, comprehensive time scales, and strategies of implementation based on the study outcomes. A set of final recommendations at different micro-, meso-, and macrolevels have been complementarily included at this stage to support the previous parts of the implementation process.

The results of the systematic methodological approach in each part are fully presented as a detailed subsection, including the characterization of the variables involved, namely, the technical objective (TO) resume definition; the considered main study input information sources; the proposed specific objectives ( $\mathrm{SO}$ ) and the corresponding reference questions (RQ) to be addressed at the final stage; a resume and short contextualization on the associated theoretical output contents (OC) per question; and the selected final output format of each part.

A final schematic is presented in Guideline structure subsection for a better understanding and an overview of the different parts of the methodological process integration. External links for content consultation or download are also provided, when applicable.

\section{Part 1: Industrial Symbiosis Overview}

The technical objective of Part 1 "industrial symbiosis overview," is to introduce the general concept of industrial symbiosis and the associated benefits for companies. The contents presented are mostly based on the results of "lessons learnt and best practices for enhancing industrial symbiosis in the process industry," available at [42] together with specific inputs resulting from involved stakeholders and IS experts' suggestions [39]. The following set of dedicated reference questions (RQ) were idealized together with their expected output contents (OC) to support each SO:

RQ1. What is industrial symbiosis? where the associated output contents provide an easily understandable and applied perspective definition (OC1).

RQ2. What are the key benefits of IS Implementation? where the associated output contents are based on the identification of the main advantages of the IS process, 


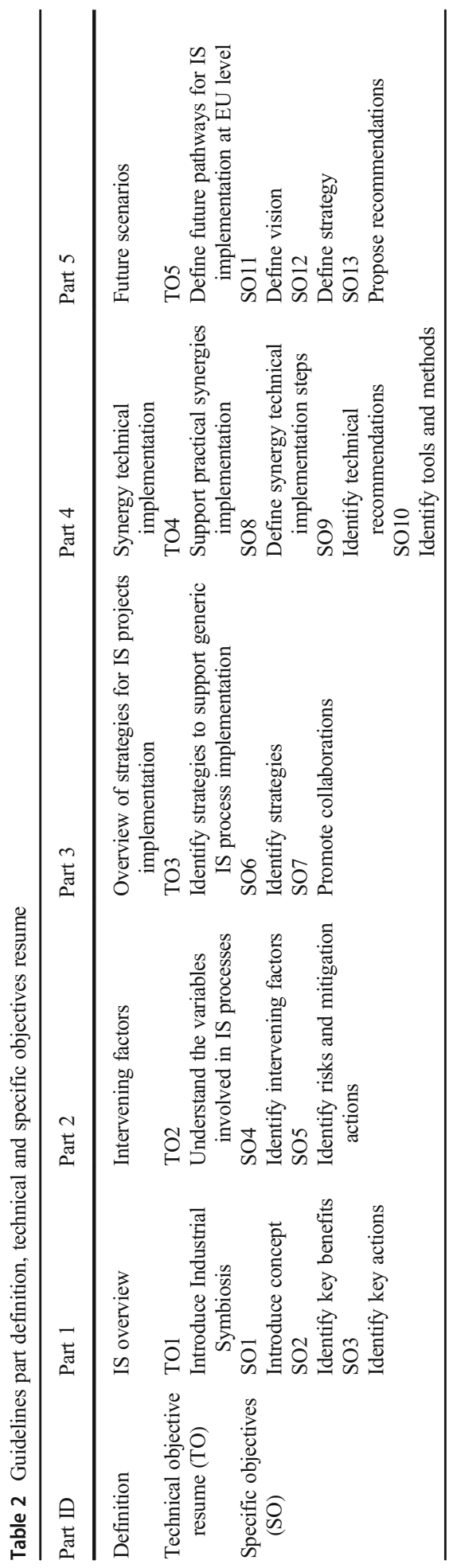


together with some successful examples of its implementation (OC2).

RQ3. What are the key actions for IS implementation? where output contents present the core actions to be considered from an industrial perspective regarding IS process implementation (OC3).

The output format chosen for Part 1 is a multilanguage short animation video due not only to its simplicity of understanding but also looking for the high acceptability and dissemination potential associated with media platforms.

\section{Part 2: Intervening Factors}

The technical objective of Part 2, "intervening factors," aims to facilitate the understanding of the main variables involved and that can affect positively and negatively an IS process implementation. The contents presented have been mostly based on the results of "lessons learnt and best practices for enhancing industrial symbiosis in the process industry," where key factors identified as enablers, barriers, and incentives in the emerging process of IS are presented [39]. While in "how to create incentives for industrial symbiosis while preventing and mitigating implementation risks," a complete IS implementation risks perspective and mitigation actions are presented [41] and considered in this study.

The following set of dedicated reference questions (RQ) have been idealized together with their expected output contents (OC) to support each SO:

RQ4. What are the intervening factors for industrial symbiosis implementation? where the associated output contents provide a detailed overview of the barriers, incentives, and enablers per each dimension involved in the process (social, economic, policy, technology, intermediaries, geographical) (OC4).

RQ5. What are the risks and mitigation actions in the emerging process for IS? where the associated output contents are based not only on the identification and characterization of main risks associated with IS process implementation but also on a set of associated mitigation actions (OC5).

The final output format chosen for Part 2 corresponds to an infographic document that visually organizes and compiles the core information and promote its further utilization as a compact didactic material for IS dissemination activities, users' guidance, and stakeholder engagement.

\section{Part 3: Overview of Strategies for IS Projects Implementation}

The technical objective of Part 3, "overview of strategies for IS projects implementation," allows to support generic IS implementation. The contents presented are mostly based on the results of "Lessons learnt and best practices for enhancing industrial symbiosis in the process industry," where a full description of IS emerging process and how to reinforce them is available [39], and the "overall strategy and recommendations to foster a wide application of industrial symbiosis at local, regional, and European level" where a summary of strategies and recommendations is presented[50].

The following set of dedicated reference questions (RQ) have been idealized together with their expected output contents (OC) to support each SO:

RQ6. Which are the strategies for IS? where the associated output contents identify core actions and clear strategies to be considered at the company, regional/national, and 
European levels (OC6).

RQ7. How to enhance and foster collaboration (finding partners, networks, build trust, confidence)? where the associated output contents provide the generic principles to be considered before and during the first stages of IS coordinated network establishment (OC7).

The final output format chosen for Part 3 is an infographic document that identifies key actions to be considered and provides general recommendations and strategies to foster cooperation and reinforce the emerging process of IS at organizational, regional/national, and European levels.

\section{Part 4: Synergy Technical Implementation}

The technical objective of Part 4, "synergy technical implementation," is to support the technical implementation of a synergy in its different domains. The contents presented are mostly based on the results of "the role of intermediaries and enabling technologies for identification and implementation of industrial symbiosis" [43]; "pathways to increase industrial symbiosis including tools and methods for stakeholders" [44]; "technology database template \& guide for upgrading" [46]; "synergies environmental impact assessment" [47], and "synergies socio-economic impact assessment" [48].

The following set of dedicated reference questions (RQ) have been idealized together with their expected output contents (OC) to support each SO:

RQ8. What is a synergy and how to technically implement a synergy step by step? where the associated output contents provide a step-by-step description of all stages involved in an IS exchange (OC8).

RQ9. What are the general technical recommendations?/good Practice of implementation? where the associated output contents identify and characterize a full set of good practices for implementation and propose associated technical recommendations (O9). RQ10. Which are the enabling tools (and methods) for IS implementation and for what specific purpose (what, when to use them) in the technical implementation steps? where the associated output contents compile a set of pre-identified tools including generic and specific tools and toolkits associated with the synergy technical implementation process (OC 10).

The final output format chosen for Part 4 corresponds to an infographic document that presents a dedicated overview on how to technically implement a synergy, including the identification of the different stages and processes involved, and a detailed compilation analysis regarding the tools and methods available for industrial symbiosis practitioners.

\section{Part 5: Future Scenarios}

Complementarily to the aforementioned parts, associated with the implementation process itself, emerges the need of contextualizing and support the creation of a clear vision of the ideal scenarios for a large implementation of IS at the European level, namely, to define an intervention timeline strategy for their implementation and provide a set of recommendations for practitioners at different levels that promote and facilitate the implementation of the different parts. 
The technical objective of Part 5, "future scenarios," aims to compile the project information regarding the deployment of the study vision and overall strategy and recommendations for industrial symbiosis. The contents presented are mostly based on the results of the "overall strategy and recommendations to foster a wide application of industrial symbiosis at local, regional, and European level" [50].

The following set of dedicated reference questions (RQ) have been idealized together with their expected output contents (OC) to support each SO:

RQ11. What are the best scenarios and vision for IS implementation? where the associated output contents will clearly define an implementation pathway and vision to promote a wider application of IS based on the integration of multiple best-case scenarios. (OC11).

RQ12. What is the strategy for 10-year IS implementation process? where the associated output contents propose a roadmap strategy according to the proposed vision for short(1-3years); medium- (3-5 years), and long-term (5-10 years) actions (OC12).

RQ13. What are the general recommendations for IS implementation at the local/ regional level? where the associated output contents compile a full set of recommendations at the Local /Regional/ European level to increase the benefits that would derive from a massive application of IS and support the vision in the mid $(\sim 5)$ and long-term ( 10 years) (OC13).

The final output format chosen for Part 5 corresponds to an infographic document that compiles the project information regarding SCALER Vision and best Scenario, SCALER 10-year implementation strategy, recommendations for IS (local/regional/national levels).

\section{Guideline Structure}

The final guideline schematic structure is presented in Fig. 4. A sequential overview of the main parts and the final contents involved is summarized and visually integrated for a better understanding and interpretation of the above presented methodology. The final guidelines for industrial symbiosis ready to be used and achieved from the systematic approach application presented in this paper is fully available for consultation and to be downloaded at [52].

\section{Conclusions and Recommendations}

This paper presents a systematic approach methodology for IS guideline content definition, integrating into a comprehensive structure the instruments and methods for information sources assessment and their correlation with the final content and practical output definition. The systematic approach arises from the crossing of different methods such as the compilation and synthetization of extensive literature reviews, dedicated inquires, and expert consultation activities.

A total of five sequential and independent information clusters named as parts have been defined to cover the different stages of a full IS implementation process. A detailed description of each part is presented together with the characterization of the variables involved and the systematic approach used for each one. The final practical output of the study is an integrated 


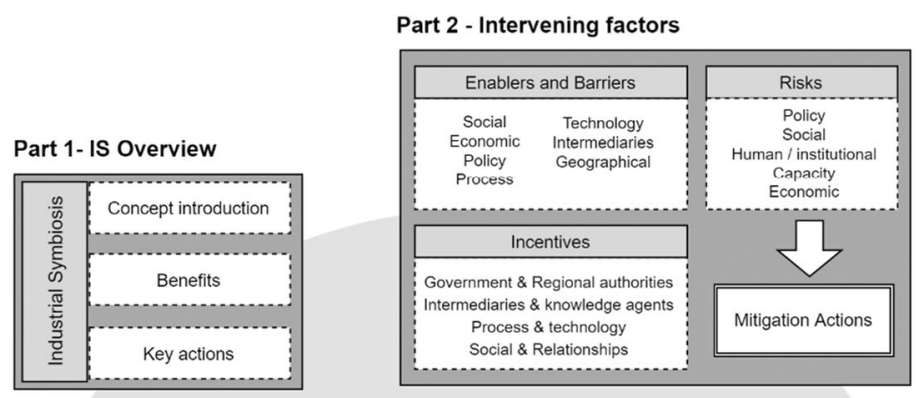

Part 5 - Future Scenarios

\begin{tabular}{|c|}
\hline Vision \\
Investment and Intermediaries \\
Syne gy Selection \\
Synergy validation \\
Technology selection \\
\hline Strategy \\
3-5 years Regional/National strategies \\
1-2 years Local Tactics \\
years Integrated Europe Circular Economy \\
Recommendations \\
Regional / National \\
European
\end{tabular}

Part 3 - Overview of Strategies

\begin{tabular}{|c|}
\hline Company level \\
\hline Change waste mindset \\
Waste value proposition \\
Business model innovation \\
Strong leadership and commitment \\
Network establishment \\
\hline Regional / National level \\
\hline Material flow mapping \\
Engagement policies \\
Best practice dissemination \\
Engage as facilitators \\
Support and manage IS \\
\hline European level \\
\hline Create waste market regulation \\
Promote standardisation \\
Financial Incentives \\
Promote IS private Investment \\
Establish Metrics and targets \\
\hline
\end{tabular}

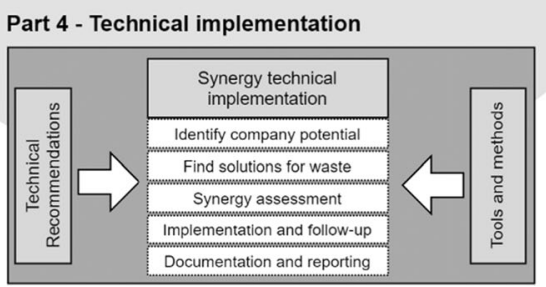

Fig. 4 Guidelines schematic structure resume

guideline structure for IS implementation, including the stand-alone output document parts that could be accessed individually by practitioners. The dynamic and flexible character of the systematic methodologic approach presented facilitates the incorporation, upgrade, and adaptation of new contents according to specific purposes and results from ongoing and future studies regarding industrial symbiosis.

The guideline, so far, has been based on theoretical and empirical knowledge derived from a dedicated sample of stakeholders within the scope of this study. A practical validation is to follow by applying the proposed guidelines at company, regional/national and European level contexts. Due to the applied and structured character of the final practical guidelines, these can support the development of a dedicated handbook for industrial symbiosis, that would drive and accelerate the understanding, acceptance, and applicability of large-scale intersectoral full IS implementation processes. 


\section{Glossary \\ EU European Union \\ ISIndustrial symbiosis \\ PDFPortable document format \\ T4ISToolkit for industrial symbiosis}

Funding This study has received funding from the European Union's Horizon 2020 research and innovation programs under grant agreement "No. 768748" and under grant agreement "No. 810764."

Declarations The manuscript has been prepared according to the Journal's Instruction for Authors. We confirm that this manuscript has not been published elsewhere and is not under consideration by another journal. We have no conflicts of interest to disclose.

Conflicts of Interest The authors declare no conflict of interest.

Open Access This article is licensed under a Creative Commons Attribution 4.0 International License, which permits use, sharing, adaptation, distribution and reproduction in any medium or format, as long as you give appropriate credit to the original author(s) and the source, provide a link to the Creative Commons licence, and indicate if changes were made. The images or other third party material in this article are included in the article's Creative Commons licence, unless indicated otherwise in a credit line to the material. If material is not included in the article's Creative Commons licence and your intended use is not permitted by statutory regulation or exceeds the permitted use, you will need to obtain permission directly from the copyright holder. To view a copy of this licence, visit http://creativecommons.org/licenses/by/4.0/.

\section{References}

1. Erkman S (1997) Industrial ecology: an historical view. J Clean Prod 5:1-10. https://doi.org/10.1016/s09596526(97)00003-6

2. Lombardi DR, Laybourn P (2012) Redefining industrial symbiosis. J Ind Ecol 16:28-37. https://doi.org/10. 1111/j.1530-9290.2011.00444.x

3. Short SW, Bocken NMP, Barlow CY, Chertow MR (2014) From refining sugar to growing tomatoes. J Ind Ecol 18:603-618. https://doi.org/10.1111/jiec.12171

4. Fraccascia L, Magno M, Albino V (2016) Business models for industrial symbiosis: a guide for firms. Procedia Environ Sci Eng Manag 3:83-93

5. Fraccascia L, Giannoccaro I, Albino V (2019) Business models for industrial symbiosis: a taxonomy focused on the form of governance. Resour Conserv Recycl 146:114-126. https://oi.org/10.1016/j. resconrec.2019.03.016

6. Boix M, Montastruc L, Pibouleau L, Azzaro-Pantel C, Domenech S (2012) Industrial water management by multiobjective optimization: from individual to collective solution through eco-industrial parks. J Clean Prod 22:85-97. https://doi.org/10.1016/j.jclepro.2011.09.011

7. Kurdve M, Jönsson C, Granzell AS (2018) Development of the urban and industrial symbiosis in western Mälardalen. Procedia CIRP 73:96-101. https://doi.org/10.1016/j.procir.2018.03.321

8. Mirata M (2004) Experiences from early stages of a national industrial symbiosis programme in the UK : determinants and coordination challenges. J Clean Prod 12:967-983. https://doi.org/10.1016/j.jclepro.2004. 02.031

9. Boons F, Chertow M, Park J, Spekkink W, Shi H (2017) Industrial symbiosis dynamics and the problem of equivalence: proposal for a Comparative Framework. J Ind Ecol 21:938-952. https://doi.org/10.1111/jiec. 12468

10. Domenech T, Bleischwitz R, Doranova A, Panayotopoulos D, Roman L (2019) Mapping industrial symbiosis development in Europe_typologies of networks, characteristics, performance and contribution to the Circular Economy. Resour Conserv Recycl 141:76-98. https://doi.org/10.1016/j.resconrec.2018.09. 016

11. Yu F, Han F, Cui Z (2015) Evolution of industrial symbiosis in an eco-industrial park in China. J Clean Prod 87:339-347. https://doi.org/10.1016/j.jclepro.2014.10.058 
12. Neves A, Godina R, G. Azevedo S, et al. (2019) The potential of industrial symbiosis: case analysis and main drivers and barriers to its implementation. Sustainability 11:7095. https://doi.org/10.3390/su11247095

13. Chertow MR (2007) "Uncovering” industrial symbiosis. J Ind Ecol 11:11-30. https://doi.org/10.1162/jiec. 2007.1110

14. Song X, Geng Y, Dong H, Chen W (2018) Social network analysis on industrial symbiosis: a case of Gujiao eco-industrial park. J Clean Prod 193:414 423. https://doi.org/10.1016/j.jclepro.2018.05.058

15. Yu C, Davis C, Dijkema GPJ (2014) Understanding the evolution of industrial symbiosis research: a bibliometric and network analysis (1997-2012). J Ind Ecol 18:280-293. https://doi.org/10.1111/jiec.12073

16. Islam K, Islam KN, Rahman MF (2016) Industrial symbiosis: a review on uncovering approaches, opportunities, barriers and policies. J Civ Eng Environ Sci 2:11-19. https://doi.org/10.17352/2455-488x. 000008

17. Golev A, Corder GD, Giurco DP (2014) Barriers to industrial symbiosis insights from the use of a maturity grid. J Ind Ecol 19:141-154. https://doi.org/10.1111/jiec.12159

18. Mirata M, Emtairah T (2005) Industrial symbiosis networks and the contribution to environmental innovation: the case of the Landskrona industrial symbiosis programme. J Clean Prod 13:993-1002. https://doi.org/10.1016/j.jclepro.2004.12.010

19. Domenech T, Davies M (2011) Structure and morphology of industrial symbiosis networks: the case of Kalundborg. Procedia Soc Behav Sci 10:79-89. https://doi.org/10.1016/j.sbspro.2011.01.011

20. Albino V, Fraccascia L (2015) The industrial symbiosis approach: a classification of business models. Procedia Environ Sci Eng Manag 2:217-223

21. Yang S, Feng N (2008) A case study of industrial symbiosis: Nanning Sugar Co., Ltd. in China. Resour Conserv Recycl 52:813-820. https://doi.org/10.1016/j.resconrec.2007.11.008

22. Costa I, Ferrão P (2010) A case study of industrial symbiosis development using a middle-out approach. J Clean Prod 18:984-992. https://doi.org/10.1016/j.jclepro.2010.03.007

23. Park HS, Rene ER, Choi SM, Chiu ASF (2008) Strategies for sustainable development of industrial park in Ulsan, South Korea-From spontaneous evolution to systematic expansion of industrial symbiosis. J Environ Manag 87:1-13. https://doi.org/10.1016/j.jenvman.2006.12.045

24. Zhu Q, Lowe EA, Wei YA, Barnes D (2007) Industrial symbiosis in China: a case study of the Guitang Group. J Ind Ecol 11:31-42. https://doi.org/10.1162/jiec.2007.929

25. Tao Y, Evans S, Wen Z, Ma M (2019) The influence of policy on industrial symbiosis from the Firm's perspective: a framework. J Clean Prod 213:1172-1187. https://doi.org/10.1016/j.jclepro.2018.12.176

26. Boons F, Spekkink W, Isenmann R et al (2015) Comparing industrial symbiosis in Europe: towards a conceptual framework and research methodology. In: International Perspectives on Industrial Ecology. Edward Elgar Publishing, Cheltenham, pp 69-88

27. European Commission (2020) Study and portfolio review of the projects on industrial symbiosis in DG Research and Innovation: findings and recommendations. https:/ec.europa.eu/info/publications/study-andportfolio-review-projects-industrial-symbiosis-dg-research-and-innovation-findings-and-recommendations en. .

28. European Commission (2018) Cooperation fostering industrial symbiosis market potential, good practice and policy actions. https://op.europa.eu/pt/publication-detail/-/publication/174996c9-3947-11e8-b5fe01aa75ed71a1/language-en. .

29. University of Cambridge (2020) Dictionary Cambridge. https://dictionary.cambridge.org/pt/dicionario/ ingles-portugues/guideline

30. Johnsen I, Berlina A, Lindberg G, et al. (2015) The potential of IS as a key driver of green growth in Nordic regions. https://nordregio.org/publications/industrial-symbiosis-a-key-driver-of-green-growth-in-nordicregions/.

31. Moodie J, Salolammi P (2019) 11 Steps to implement industrial symbiosis. http://nordregio.org/11-steps-toimplement-industrial-symbiosis/.

32. Holgado M, Evans S, Benedetti M et al (2019) MAESTRI toolkit for industrial symbiosis: overview, lessons learnt and implications. In: Smart Innovation, Systems and Technologies, pp 51-60. https://doi.org/ 10.1007/978-3-030-04290-5 6

33. Holgado M (2017) User guide to engage in industrial symbiosis through the T4IS. https://maestri-spire.eu/ wp-content/uploads/2018/01/User-Guide-T4IS-final-version.pdf. .

34. Washington State Department of Commerce, International Synergies, Sustainable Center for, Infrastructure (2019) Industrial waste coordination (Industrial Symbiosis) program recommendations. http://www. commerce.wa.gov/wp-content/uploads/2019/12/Industrial-Waste-Coordination-Industrial-SymbiosisReport.pdf.

35. (2020) Sharebox Project. http://sharebox-project.eu/\#overview. .

36. (2020) FISSAC - Fostering industrial symbiosis for a sustainable resource intensive industry across the extended construction value chain. http://fissacproject.eu/en/. . 
37. Chambers of Commerce Molise (2017) SYMBY project report: good practice guide and benchmarking guidelines on ecosystems of byproduct and energy exchanges. https://www.interregeurope.eu/fileadmin/ user_upload/tx_tevprojects/library/SYMBI_A1.3_Good\%20practice\%20guide\%20on\%20eco\%20systems. pdf. .

38. Henriques J, Azevedo J, Dias R, et al. (2020) Industrial symbiosis incentives: mitigating risks for facilitated implementation. https://doi.org/10.5281/zenodo.3964127.

39. Vladimirova D, Miller K, Evans S (2018) Scaler deliverable 2.1: lessons learnt and best practices for enhancing industrial symbiosis in the process industry. https:/www.scalerproject.eu/wp-content/uploads/ 2019/07/Lessons-Best-practices-SCALER-D2.2.pdf. .

40. Madsen JK, Boisen N, Nielsen LU, Tackmann LH (2015) Industrial symbiosis exchanges: developing a guideline to companies. Waste Biomass Valoriz 6:855-864. https://doi.org/10.1007/s12649-015-9417-9

41. Henriques J, Estrela M, Ascenço C, et al. (2019) Scaler deliverable 2.3: how to create incentives for industrial symbiosis. https://www.scalerproject.eu/wp-content/uploads/2019/07/Incentives-assessmentReport-SCALER-D2.3.pdf.

42. (2017) SCALER-Scaling for industrial symbiosis and efficiency resource project. In: Grant Agreem. no 768748 https://www.scalerproject.eu/.

43. Vladimirova D, Miller K, Evans S (2018) Scaler deliverable 2.2: intermediaries \& key enabling technologies. https:/www.scalerproject.eu/wp-content/uploads/2019/07/Intermediaries-Technologies-SCALERD2.1.pdf.

44. Vladimirova D, Miller K, Evans S (2019) Scaler deliverable 2.4: pathways to increase Industrial Symbiosis. ht5tps://www.scalerproject.eu/wp-content/uploads/2019/07/Pathways-to-increase-industrial-symbiosisSCALER-D2.4.pdf.

45. Stéphane O, Jean-Baptiste Q, Charles-Xavier S et al (2019) A cross-sectorial synergies identification methodology for industrial symbiosis. In: Smart Innovation, Systems and Technologies

46. Azevedo J, Dias R, Ferreira I, et al. (2019) Scaler deliverable 3.2 - technology database template and guide for update. https://www.scalerproject.eu/wp-content/uploads/2019/10/Technology-database-for-synergiessetup-SCALER-D3.2.pdf.

47. Lessard L, Laffely J (2019) Scaler deliverable 3.3: synergies environmental impact assessment. https:// www.scalerproject.eu/wp-content/uploads/2019/10/Synergies-environmental-impact-assessment-SCALERD3.3.pdf.

48. Quintana J (2019) Scaler deliverable 3.4 : synergies socio-economic impact assessment. https://www. scalerproject.eu/wp-content/uploads/2019/10/Synergies-socio-economic-impact-assessment-SCALER-D3. 4.pdf.

49. Quintana J-B, Chamikhi R, Bremidas A (2020) Scaler deliverable 3.4: quantified potential of industrial symbiosis in Europe. https:/www.scalerproject.eu/wp-content/uploads/2020/06/D3.5_SCALER_ Quantified-potential-of-industrial-symbiosis-in-Europe_v1.0.pdf.

50. Vladimirova D, Azevedo J, Dias R, et al. (2020) Scaler Deliverable 4.1: overall strategy and recommendations to foster a wide application of industrial symbiosis at local, regional and European level.https:// www.scalerproject.eu/wpcontent/uploads/2020/06/D4.1_SCALER_Overall_strategy_and_ recommendations_v1.0.pdf.

51. Dias R, Azevedo J, Ferreira I, Estrela M, Henriques J, Ascenço C, Iten M (2020) Technical viability analysis of industrial synergies-an applied framework perspective. Sustainability 12:1-15. https://doi.org/10.3390/ su12187720

52. Azevedo J, Henriques J, Dias R, Estrela M (2020) Scaler deliverable 4.2: guidelines for industrial symbiosis. https://www.scalerproject.eu/resources/guides-outlooks. 


\section{Affiliations}

João Azevedo ${ }^{1} \cdot$ Juan Henriques $^{1} \cdot$ Marco Estrela $^{2} \cdot$ Rui Dias $^{1} \cdot$ Doroteya Vladimirova $^{3}$. Karen Miller $^{3} \cdot$ Muriel Iten ${ }^{1}$

Juan Henriques

jdhenriques@isq.pt

Marco Estrela

maestrela@isq.pt

Rui Dias

radias@isq.pt

Doroteya Vladimirova

dkv21@cam.ac.uk

Karen Miller

km531@cam.ac.uk

Muriel Iten

muriel.iten@gmail.com

1 Low Carbon \& Resource Efficiency, R\&Di, Instituto de Soldadura e Qualidade, Rua do 8 Mirante, 33, 4415-491 Grijo, Portugal

2 Low Carbon \& Resource Efficiency, R\&Di, Instituto de Soldadura e Qualidade, Av. Prof. Dr. Cavaco Silva, 258, Taguspark, 2740-120 Oeiras, Portugal

3 Institute for Manufacturing, Department of Engineering, University of Cambridge, 17 Charles Babbage Road, Cambridge CB3 OFS, UK 